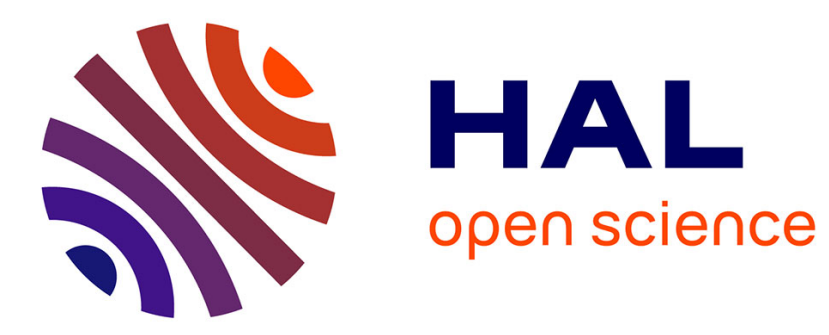

\title{
Roughness Influence on Human Blood Drop Spreading and Splashing
}

\author{
Fiona Smith, Naomi C Buntsma, David Brutin
}

\section{To cite this version:}

Fiona Smith, Naomi C Buntsma, David Brutin. Roughness Influence on Human Blood Drop Spreading and Splashing. Langmuir, 2017, 34 (3), pp.1143 - 1150. 10.1021/acs.langmuir.7b02718 . hal01769984

\section{HAL Id: hal-01769984 \\ https://hal.science/hal-01769984}

Submitted on 20 Apr 2018

HAL is a multi-disciplinary open access archive for the deposit and dissemination of scientific research documents, whether they are published or not. The documents may come from teaching and research institutions in France or abroad, or from public or private research centers.
L'archive ouverte pluridisciplinaire HAL, est destinée au dépôt et à la diffusion de documents scientifiques de niveau recherche, publiés ou non, émanant des établissements d'enseignement et de recherche français ou étrangers, des laboratoires publics ou privés. 


\title{
Roughness influence on human blood drop spreading and splashing
}

\author{
Fiona R. Smith, Naomi C. Buntsma, and David Brutin* \\ Aix Marseille Univ, CNRS, IUSTI, Marseille, France \\ E-mail: fiona.smith@univ-amu.fr;david.brutin@univ-amu.fr \\ Phone: +33 (0)4 911069 07. Fax: +33 (0)4 91106868
}

\begin{abstract}
Bloodstain Pattern Analysis (BPA) is used on a daily basis as evidence in crime scene reconstruction. However though the impact behaviour of complex fluid droplets have been extensively studied, important questions still remain. We investigate the influence of surface roughness and wettability on the splashing limit of droplets of blood, a non-Newtonian colloidal fluid. Droplets of blood impacting perpendicularly different surfaces at different velocities were recorded with a high-speed camera. The recordings were analysed as well as the surfaces characteristics in order to find an empirical solution since we found that roughness plays a major role in the threshold of the splashing/non-splashing behaviour of blood compared to the wettability. Moreover it appears that roughness alters the deformation of the drip stains. These observations are key to characterising features of drip stains with the impacting conditions, yielding a more complete forensic analysis in certain cases.
\end{abstract}
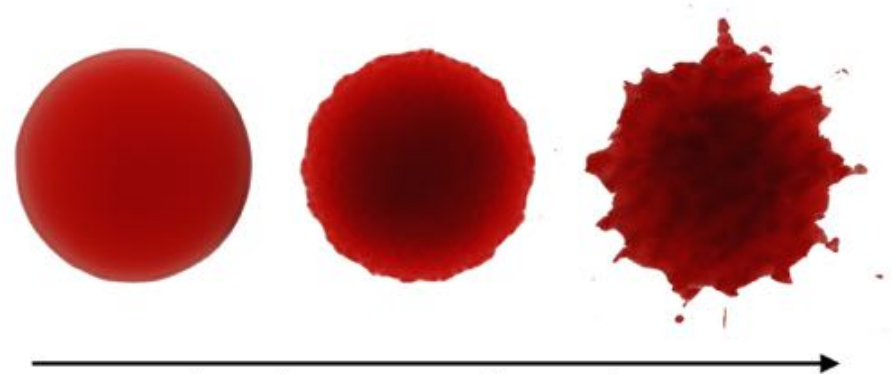

Increasing average surface roughness for impact velocity of $2.6 \mathrm{~m} . \mathrm{s}^{-1}$

\section{Introduction}

Newtonian fluid drops impacting a dry surface follow a temporal development as described by Josserand and Thoroddsen ${ }^{1}$ in their extensive review. This development will differ according to the surfaces properties, the impact characteristics and the gas properties. Four distinct phases were defined, the kinematic phase, the spreading phase, the relaxation phase and the wetting/equilibrium phase ${ }^{2}$. High velocity impacts on rough surfaces will favour splashing, which is defined as the break-up of the main drop leading to one or several secondary drops. Different splashing behaviours were observed and largely studied for the past century. The main features which were identified led to the following classification: deposition, corona splash, prompt splash, receding break-up, and partial or full rebound ${ }^{3,4,5}$ as shown in figure 1, from the review of Marengo et al. ${ }^{4}$ on the topic. They underlined that no final correlation is found yet, but that a defined approach exists and suggested to use the present understanding of the problem of drop impact of Newtonian fluids $6,7,8$ onto simple smooth and flat surfaces as shown in table 1 for a better modelling of more complicated cases.

The various industrial applications of impacting droplets account for such curiosity and relevant research. Our interest is focused on a different application: the forensic field, and thus on the outcome of blood, a non-Newtonian fluid, impacting different non-porous surfaces. 
Table 1: Overview of studies on the splashing behaviour of different Newtonian fluids on different dry surfaces

\begin{tabular}{|c|c|c|c|c|}
\hline Year & Authors & Fluids & Surfaces & $\begin{array}{l}\text { velocities } \\
\left(\mathrm{m} . \mathrm{s}^{-1}\right)\end{array}$ \\
\hline 2017 & Tang et al. & $\begin{array}{l}\text { water, ethanol, decane, } \\
\text { tetradecane }\end{array}$ & stainless steel & $0.5-5.2$ \\
\hline 2016 & $\begin{array}{l}\text { Chamakos et } \\
\text { al. }\end{array}$ & glycerin/water mixtures & wax solid surface & 1.05 \\
\hline 2015 & Roisman et al. & $\begin{array}{l}\text { isopropyl alcohol, glycerol } \\
95 \%, \text { water }\end{array}$ & $\begin{array}{l}\text { bronze, ceramic, glass, } \\
\text { PTFE, PE, stainless steel }\end{array}$ & $0-8$ \\
\hline 2012 & Latka et al. & $\begin{array}{l}\text { ethanol, silicon oil, wa- } \\
\text { ter/glycerin mixtures }\end{array}$ & $\begin{array}{l}\text { sand paper, glass slides } \\
\text { etched with ammonium } \\
\text { bifluoride, acrylic plates }\end{array}$ & $2.7-4.1$ \\
\hline 2012 & Antonini et al. & water & $\begin{array}{l}\text { untreated smooth glass, } \\
\text { PMMA, teflon, SHS } \\
\text { teflon, OTSa, OTSb, } \\
\text { OTSc, OTSd }\end{array}$ & $0.90-4.2$ \\
\hline 2010 & Gipperich et al. & water, isopropanol & $\begin{array}{l}\text { bronze, stainless steel, } \\
\text { glass, PE, PTFE }\end{array}$ & $0.46-5.13$ \\
\hline 2010 & Palacios et al. & $\begin{array}{l}\text { glycerol and water } \\
\text { mixtures, water, bu- } \\
\text { tanol, propanol, ethanol, } \\
\text { methanol }\end{array}$ & dry glass & $1.1-4.5$ \\
\hline 2006 & $\begin{array}{l}\text { Wander val et } \\
\text { al. }\end{array}$ & $\begin{array}{l}\text { heptane, hexadecane, } \\
\text { ethanol, water, } 30 \% \\
\text { glycerol/water mixture }\end{array}$ & $\begin{array}{ll}\text { carbide steel, } & \text { dry } \\
\text { diamond-lathed } & \text { alu- } \\
\text { minum disk, thin fluid } \\
\text { films }\end{array}$ & $2.17-4.22$ \\
\hline 2005 & $\mathrm{Xu}$ et al. & $\begin{array}{l}\text { methanol, ethanol, } 2- \\
\text { propanol }\end{array}$ & dry glass & $2-7$ \\
\hline 2002 & Rioboo et al. & $\begin{array}{l}\text { acetone, isopropanol, } \\
\text { ethanol, water, silicone, } \\
\text { oils and mixtures of } \\
\text { glycerine and water }\end{array}$ & $\begin{array}{l}\text { PVC, wax, glass, polymer } \\
\text { coatings }\end{array}$ & $0.78-4.1$ \\
\hline 1995 & Mundol et al. & $\begin{array}{l}\text { ethanol, water, water- } \\
\text { sucrose-ethanol mixture }\end{array}$ & $\begin{array}{l}\begin{array}{l}\text { rubber lip on rotating } \\
\text { disk }\end{array} \\
\end{array}$ & $12-18$ \\
\hline 1995 & Yarin et al. & $\begin{array}{l}\text { ethanol, or water- } \\
\text { ethanol-glycerol mixtures }\end{array}$ & $\begin{array}{l}\text { dry solid surface of } \mathrm{Rz}= \\
1 \text { or } 16 \mu \mathrm{m}\end{array}$ & up to 30 \\
\hline
\end{tabular}




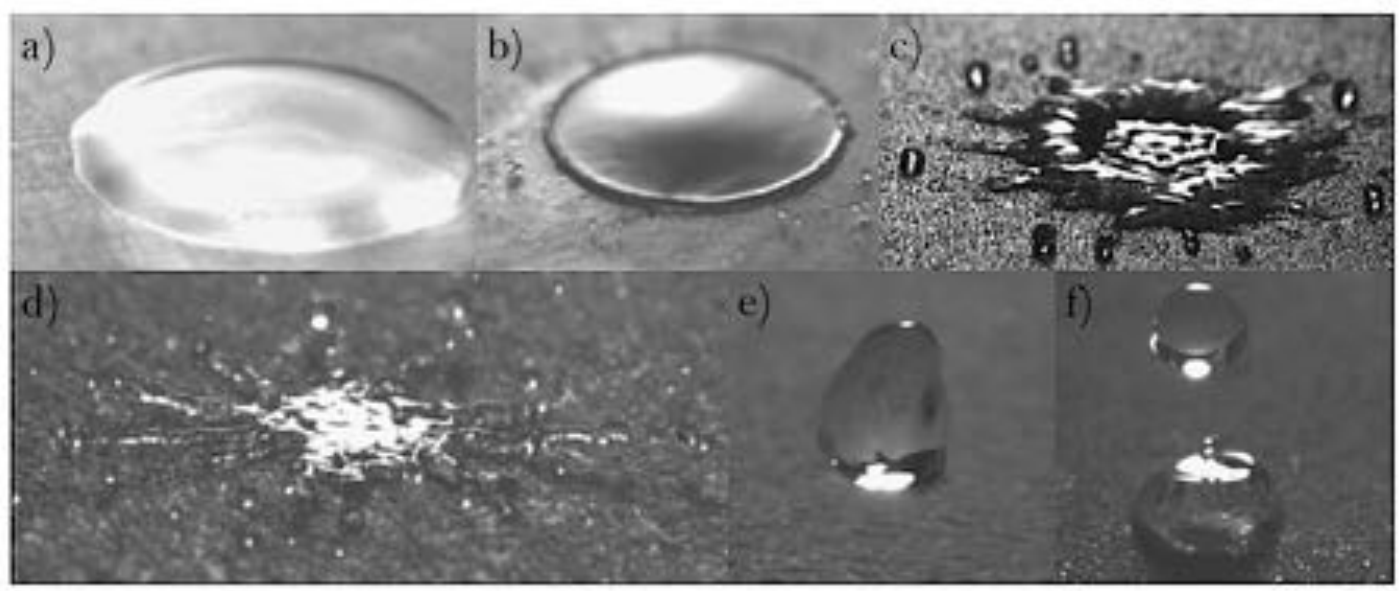

Figure 1: Outcomes of non-complex fluid droplets: a) deposition (isopropanol on rough glass), b) corona splash (isopropanol on rough ceramic), c) receding break-up (water on porous stainless steel), d) prompt splash (water on rough PE), e) rebound (water on porous PTFE), f) partial rebound (water on porous bronze) from Marengo et al.(2011).

The field of study related to blood drip stains in forensic applications falls nowadays in the large topic that is the impact of complex fluid droplets. Surface tension and viscosity are the main physical parameters involved in the wetting and the spreading of blood on solid surfaces encountered in crime scenes. As Yarin ${ }^{9}$ shows in his review, the impact velocity, the drop size, the liquid properties as well as nonNewtonian effects in cases of complex fluids, the surface tension, the roughness and the wettability of the solid surface determine the outcome of the drop impact. To define the impact dynamics, the dimensionless Weber and Reynolds numbers are commonly used since they describe the liquid properties and the impact. Therefore, we use the Weber number (We $=\rho D_{0} U^{2} / \sigma$ ), which is the ratio between capillary and inertial forces and the Reynolds number $\left(\operatorname{Re}=\rho D_{0} U / \eta\right)$ which is the ratio between the viscous and the inertial forces. $\rho$, $\eta$ are respectively the blood density and viscosity. $\sigma$ is the blood/air surface tension. U stands for the impact velocity of the droplet, and $D_{0}$ for the initial drop diameter. Another commonly used parameter in the determination of the splashing/non-splashing outcome, is the splashing parameter $\mathrm{K},\left(K=W e^{1 / 2} R e^{1 / 4}\right)$ proposed by Mundo et al. ${ }^{10}$. This work focuses on blood drip stains, which correspond to droplets of blood resulting from the effect of gravity on open-wounds, or on a surface saturated with blood $^{11}$. They detach themselves, fall naturally and impact a horizontal surface at an angle of $90^{\circ}$, without any added energy.

\section{Materials and methods}

In order to study the impact of blood droplets at different impact energies, the impacts of droplets on different surfaces from different heights were recorded with a high-speed camera. Pictures just after impact, and after drying, were taken. To study the influence of the surface properties on the impact, for each surface, roughness and wettability were characterised.

\section{Blood properties}

Blood is sampled from healthy volunteers, stored it in sterile tubes coated with EDTA (Ethylenediaminetetraacetic acid) anticoagulant (BD Vacutainer $4 \mathrm{~mL}$ tubes spray-coated with $K_{2}$ EDTA) and kept in a refrigerator at $+5^{\circ} \mathrm{C}$. The blood is then used within two days to avoid blood ageing since an important decrease of platelets concentration starts being noticeably observed after 2 days $^{12}$. Indeed red blood cells (RBCs) and platelets cannot be conserved at the same temperature, $\mathrm{RBCs}$ are conserved at a temperature of $+5^{\circ} \mathrm{C}$, whereas 
platelets between 20 and $24{ }^{\circ} \mathrm{C}$. Before being used, the blood is reheated at room temperature and gently swirled for 10 to $15 \mathrm{~min}$ on rollers. The blood is then collected with a 200 $\mu \mathrm{L}$ electronic Eppendorf pipette. A new needle and at a new plastic tip are used for every new blood collection in order to avoid blood aggregation. Hematologic analysis (Mindray BC 3600 ) is performed giving precise information concerning the composition of blood, namely the haematocrit concentration of the different bloods, which have concentrations comprised in the range 41.0 to $47.2 \pm 0.1 \%$ for women and men. This contributes to the known small blood density variation between 1020 and 1060 $\mathrm{kg} . \mathrm{m}^{-3}$. Taking into account that this density variation is less than $4 \%$, a constant density of $\rho=1040 \pm 20 \mathrm{~kg} \cdot \mathrm{m}^{-3}$ was assumed for the rest of the study. Similarly the viscosity and the surface tension of blood are required to characterise the physical behaviour of blood droplets. Studies agree with the statement that blood has the shear thinning properties of nonNewtonian fluids as shown in figure 2, although it spreads like Newtonian fluids of similar vis$\operatorname{cosity}^{13}$. Thus the high-shear viscosity $\eta=4.8$ $\mathrm{mPa} . \mathrm{s}$ and the blood surface tension average value $\sigma=69.8 \mathrm{mN} . \mathrm{m}^{-1}$ are assumed as well for the rest of the study ${ }^{14}$.



Figure 2: Viscosity $\mu=\frac{\tau}{\dot{\gamma}}$ as a function of shear rate $\dot{\gamma}$ from 1 to $100 s^{-1}$ from Sobac $(2012)^{13}$.

\section{Surface characterisation}

Work on blood drip stains on porous substrates, such as fabrics, is already the concern of numerous and extensive studies ${ }^{15}$ in the field of forensic science. For that reason, in this study the focus is only on non-porous surfaces. Nine nonporous substrates, corresponding to commonly found surfaces on crime scenes and presenting apparent differences in their surface characteristics, are used. Originally twelve were used, but three of them were eliminated from the study since during the experiment, one appeared to present elastic properties, due to a paint coating, and the other two polished sufaces, presented some irregularities on their surfaces, corresponding to porous areas.

\section{Roughness characterisation}

First the roughness of the surfaces is characterised using confocal microscope measurements (STIL (Sciences et Techniques Industrielles de la Lumière) - Micromesure 2, with two different optical sensors: 4000m CCS (Chromatic Confocal Sensor) prima n2 and $150 \mathrm{~m}$ CCS prima) as shown in figure 3. Historically, and commonly, the arithmetic average roughness is used to define the roughness of a substrate, even though we may note that other parameters give additional information such as the amplitude, the direction or the asymmetry of the topography. For a $\mathrm{M} x \mathrm{~N}$ rectangular image, SPIP (Scanning Probe Image Processor) uses the following formula to calculate the arithmetic average roughness value, Sa:

$$
S a=\frac{1}{M N} \sum_{k=0}^{M-1} \sum_{l=0}^{M-1}\left|z\left(x_{k}, y_{l}\right)\right|
$$

where $\mathrm{x}, \mathrm{y}$ and $\mathrm{z}$ refer to the coordinates of the roughness profile.

The roughness properties of our surfaces are investigated by doing seven to nine scans for each of our surfaces from which we obtain the average roughness values, Sa, and their respective standard deviations as presented in table 2 . The microscope scans are obtained from different samples of the same surface, indicating dif- 
ferent locations, in order to obtain a representative average value.



Figure 3: Scanning electron microscope images of non-porous target materials used in the experiments: (A) PMMA, (B) Linoleum, (C) Melamine, (D) PVC, (E) Tile - porcelain, (F) Tile - ceramic (G) Wood - varnished (H) Wood - varnished (I) Wood - unvarnished.

\section{Contact angle characterisation}

As explained by De Wael, and Lepot ${ }^{16}$, the shape of a blood stain is determined by the wettability of the surface. Thus we use the sessile drop method (Krüss DSA30) to measure first the contact angle of blood on the different substrates, and then compare it with the contact angle of water. Before analysis, surfaces are cleaned with water and dried with compressed air. Drop shapes are fitted according to the tangent method. In order to get a representive average contact angle, measurements are performed on various samples of the same surface. Moreover, four of the surfaces are chemically treated with a non-wettable substance in order to obtain substrates with a different contact angle for the same surface roughness: both hydrophobic (treated) and hydrophilic (nontreated) situations were created. For this purpose, a household chemical compound (Axton, $1 \mathrm{~L})$ is used. Before treatment, the surfaces are cleaned with water and compressed air. Three layers of the compound are applied on the surfaces to make sure a solid layer is present that would results in hydrophobicity. Blood is used to measure the contact angles for the nine surfaces. More than 2100 blood contact angles are performed, from 174 to 367 measurements for each surface, giving an average value. To assess the uncertainty of this average value, the $1^{\circ}$ imprecision of the device was taken into account with the standard deviation obtained for each surface. We judge the uncertainty obtained too large to characterise our surfaces. Since blood is a biological fluid, despite using the best protocol to prevent ageing, small variations may occur if the blood is out for too long, inducing a change in its mechanical properties. It was decided to use water to characterise the roughness of our substrates. For the water contact angles, over 1600 measurements are performed, between 125 and 200 measurements for each surface. The contact angle characterisation of the different surfaces showed that the obtained average water contact angle is in general slightly larger than the blood contact angle, which can be explained by the presence of colloids in blood (micro particles, the red blood cells, and nano particles, the proteins) which affect the contact angle $^{17}$. Overall the average contact angle values for water are consistent with what is observed with blood, and much better standard deviation and thus uncertainties are obtained. For the rest of the study we thus use this parameter as presented in table 2 .

\section{Experimental set-up and uncer- tainties}

To test different impact energies, fourteen different heights of fall ranging from 0.5 to $146 \pm 1$ $\mathrm{cm}$ and a needle diameter of $18 \mathrm{G}(1.219 \mathrm{~mm}$ in diameter) were used. Each point was repeated minimum twice. Hence, the impact velocities ranged between $0.20 \mathrm{~m} . \mathrm{s}^{-1}$ and $4.83 \mathrm{~m} . \mathrm{s}^{-1}$, and the initial diameters of the droplets from 2.99 to $3.65 \mathrm{~mm}$. The droplets were released into a humidity of $30 \pm 5 \%$ on average and at ambiant pressure. This later condition is crucial, since the pressure of the surrounding gas is a parameter that can affect the outcome of an impacting droplet. Earlier work showed that gas is essential for splashing to occur ${ }^{18}$, as the pressure of the surrounding gas exerts a stress that 
Table 2: Substrates used for blood drop impacts. Are shown from left to right, the name of the materials used, the apparent color, the aspect, the average surface roughness and its standard deviation, the average water contact angle and its standard deviation. NW in front of the last four target materials indicates that three layers of non-wettable coating was applied.

\begin{tabular}{ccccccc}
\hline & Target material & Color & Aspect & $\mathrm{Sa}(\mu \mathrm{m})$ & $\theta$ water rec $\left(^{\circ}\right)$ & $\theta$ blood rec $\left(^{\circ}\right)$ \\
\hline$(\mathrm{A})$ & PMMA & transparent & smooth & $0.36 \pm 0.04$ & $89.3 \pm 2.7$ & $78.6 \pm 6.4$ \\
$(\mathrm{~B})$ & Linoleum & grey & rough & $34.24 \pm 0.65$ & $82.5 \pm 6.6$ & $85.0 \pm 5.1$ \\
$(\mathrm{C})$ & Melamine & white & intermediate & $6.78 \pm 0.40$ & $81.3 \pm 5.6$ & $76.2 \pm 7.7$ \\
$\left(\mathrm{C}^{*}\right)$ & NW Melamine & white & intermediate & $6.52 \pm 0.14$ & $112.0 \pm 1.6$ & $N / A$ \\
$(\mathrm{D})$ & PVC & grey & intermediate & $7.65 \pm 0.13$ & $85.0 \pm 3.8$ & $79.2 \pm 4.5$ \\
$\left(\mathrm{D}^{*}\right)$ & NW PVC & grey & intermediate & $7.22 \pm 0.62$ & $112.1 \pm 6.0$ & $N / A$ \\
$(\mathrm{E})$ & Tile - porcelain & grey & smooth & $4.34 \pm 0.19$ & $83.8 \pm 5.3$ & $64.9 \pm 11.3$ \\
$(\mathrm{~F})$ & Tile - ceramic & grey & smooth & $1.66 \pm 0.24$ & $65.6 \pm 6.2$ & $68.9 \pm 7.4$ \\
$(\mathrm{G})$ & Varnished pine wood & light & smooth & $2.60 \pm 0.22$ & $83.5 \pm 6.1$ & $77.8 \pm 7.2$ \\
$(\mathrm{H})$ & Varnished oak wood & dark & smooth & $3.70 \pm 0.77$ & $80.0 \pm 7.3$ & $75.0 \pm 10.0$ \\
$\left(\mathrm{H}^{*}\right)$ & NW Varnished oak wood & dark & smooth & $3.57 \pm 0.55$ & $108.2 \pm 4.3$ & $N / A$ \\
$(\mathrm{I})$ & Unvarnished oak wood & light & rough & $14.74 \pm 1.59$ & $89.3 \pm 8.7$ & $80.4 \pm 8.4$ \\
$\left(\mathrm{I}^{*}\right)$ & NW Unvarnished oak wood & light & rough & $14.76 \pm 2.22$ & $112.0 \pm 5.2$ & $N / A$ \\
\hline
\end{tabular}

acts to destabilise the advancing front of the spreading liquid. Splashing could thus be completely suppressed by decreasing the pressure of the surrounding gas, which has importance for applications such as in ink jet printing, but not for forensic applications. To record the impacts of droplets, we used a high-speed camera (Fastcam mini VM2) at 6400 images per second. To measure the volume of the droplet, the initial diameter of the droplet, its speed at the time of the impact, and its maximum spreading diameter we used the software imageJ to analyse the pictures recorded with the high- speed camera. Pictures after impact before and after drying of the drip stains were then taken with a camera (Canon EOS 7D digital camera, resolution: 5184 x 3456 pixels).

\section{Blood drop impact phenom-}

\section{ena}

When a drop of blood impacts a dry solid surface, it will spread, driven by inertia forces but is countered by adhesion and viscous forces as shown on figure 4 leading the drop to reach its maximum spreading diameter $D_{\max }$. It normally remains self-pinned to the surfaces, then evaporation and drying mechanisms take place. The following resulting outcome depends upon the drop, surface and surrounding properties. We discuss first the spreading phenomena, and then the splashing one.

\section{Spreading}

When a fluid drop hits a surface perpendicularly, different dynamics are involved. The early contact, which is characterised by the entrapping of the central air bubble followed by either the contact of the fluid with the solid substrate, or by its skating on a thin film layer of air, is observed in the first place, and remains a topic of debate ${ }^{1}$. In our case we focus on the later dynamics, which are characterised by the spreading and rebounding. These dynamics are influenced by the impact and the substrate parameters. The spreading of a blood droplet has already been described by two different models which explain the behaviour of our impact experiments. The first model of figure 5a follows the approach of Lee et al. ${ }^{19}$, who presented a universal solution taking into account that energy conservation is the only physical principal needed to describe the impact behaviour of droplets. The second approach in figure $5 \mathrm{~b}$, re- 


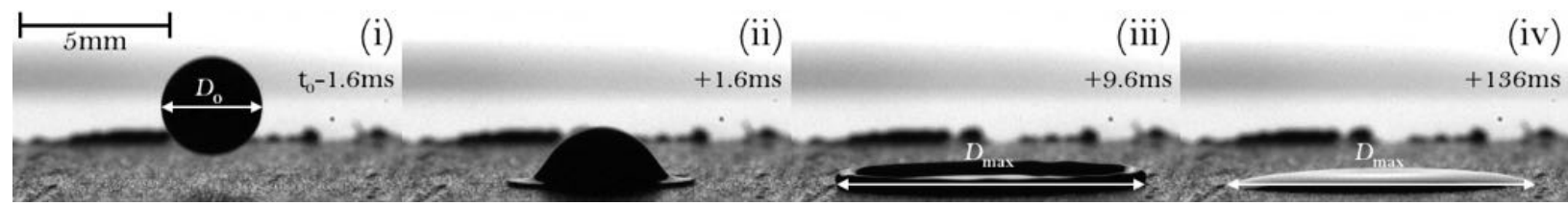

Figure 4: A blood droplet impact recorded with a high-speed camera $\left(\mathrm{U}=1.85 \mathrm{~m} . \mathrm{s}^{-1}\right.$ and $D_{0}=3.34$ $\mathrm{mm}$ ). (i) Blood droplet before its impact showing its initial diameter $D_{0}$. (ii) Impact and spreading of the droplet. (iii) The spreading reaches its maximum spreading diameter $D_{\max }$. (iv) The adhesion and viscous forces act on the droplet but the maximum diameter is unchanged due do self-pinning.

a)



b)

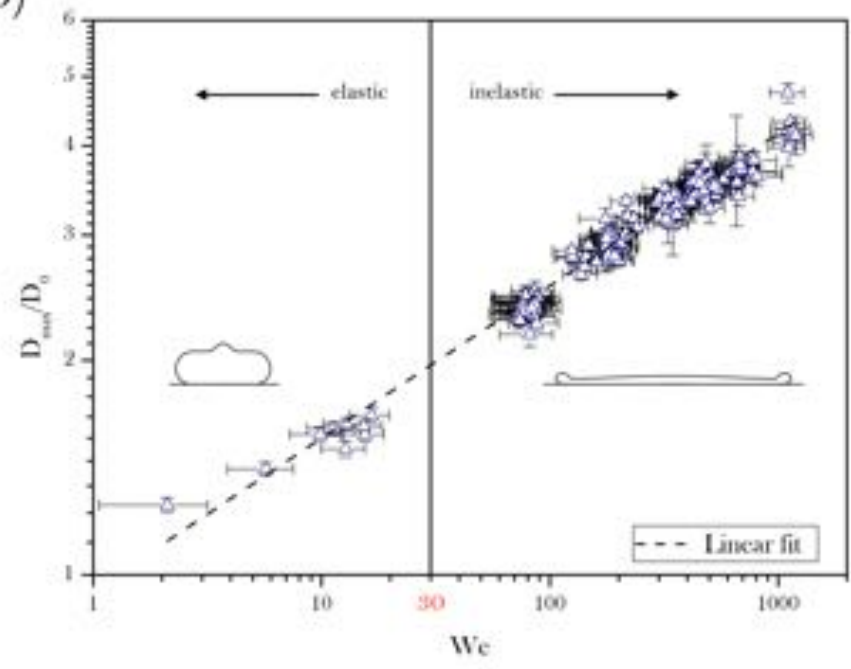

Figure 5: a) Rescaled maximum spreading ratio as a function of We. The dashed line shows the Padé approximant as used by Lee et al.(2016). b) Rescaled maximum spreading ratio as a function of Weber number according to the solution presented by Wildeman et al. (2016). The dashed line shows the trend that our experimental data set follows, which is similar to the no-slip model in the inelastic regime. lates the energy involved at impact with the dissipation mechanisms occurring on solid surfaces $^{20}$, and distinguishes two behaviours, an elastic one for low Weber numbers, less than 30 , and an inelastic one for higher weber numbers. When deformation of the drop is too much that the maximum spreading diameter cannot be measured, the droplets are excluded from these models. Anyhow, our recordings fit the models well, which would suggest that the roughness plays only a minor role in the spreading of the contact line, as these data are obtained and fit the models for very different substrates even though we believe the stain diameter might be affected by the roughness as suggested in the following studies ${ }^{21,2,22}$. The influence of the wettability is less clear. The wettability seems to only have an influence during the spreading phase: for non-wettable surfaces the drop comes to rest, earlier in time, thus limiting the maximum diameter of the stain ${ }^{9}$. However, Marengo et al. ${ }^{4}$ reported that the maximum spreading diameter is only slightly dependent on the surface wettability if the Reynolds and Weber numbers are high. Since the effect on spreading for high velocity impacts is really small, wettability is normally not accounted for. Recently, the dynamic contact angle and hence wettability was found to only influence the maximum spreading diameter for low impact velocities $^{2119}$. Moreover, by studying the maximum spreading of various liquids on various surfaces, Marengo et al. ${ }^{4}$ found that surface roughness is only important for low impact velocities, while liquid properties such as viscosity are an important factor during the complete process and suggested that the scaling used to model the maximum spreading would depend on the liquid used. 


\section{Splashing}

From the impacting drop, various outcomes may be observed: deposition, which means that no secondary droplets are observed, or splashing where at least one or more secondary droplets are observed. Splashing behaviour is divided into different categories: Corona splash, prompt splash or receding break-up. Numerous studies have focused on the different outcomes of impacting droplets, but mainly for Newtonian fluids ${ }^{23,24}$. The splashing threshold was thoroughly investigated and usually defined as the minimum drop velocity inducing the drop to break-up and to have at least one secondary droplet. Using Palacios et al. ${ }^{25}$ approach in figure 6 we investigate the splashing threshold. This model follows the work by Wal et al. ${ }^{26}$ on the splashing limit both upon a dry surface and a thin fluid film that states that the limit could be described using $\sqrt{C a}=0.35$, with $\mathrm{Ca}$ the capillary number $(\mathrm{Ca}=\mathrm{We} / \mathrm{Re})$. However, they also investigated the influence of surface roughness and found that rough surfaces lower the splashing threshold ${ }^{27}$ and this corresponds to what we observe in figure 6 and that we call the transition phase. In Roisman et al. ${ }^{3}$, they showed a well-defined map of the boundaries between deposition, prompt splash and corona splash for different Weber and Reynolds numbers. We can see that the threshold of our blood drop impacts is affected by the different surfaces used, leading to no clear boundary. From these first observations, we choose to focus the rest of our study on the influence that the surfaces properties have on this threshold.

\section{Results and discussion}

\section{Substrates properties and splash- ing threshold}

Different studies suggested that both the surface roughness and the wettability may influence the drop spreading and impact behaviour. Using high-speed recordings and the characteristics of the substrates, we are able to examine the non-splashing or splashing behaviour of the drops according to the surface properties. The



Figure 6: Weber number as a function of Reynolds number for all blood drop impact on all nine different surfaces, where either non-splashing or splashing is observed according to Palacios et al.(2010) approach. For splashing, at least one secondary stain was observed. The transition area corresponds to the zone where both splashing and nonsplashing were observed. For clarity reasons, the uncertainties are not shown.

first approach presented in figure 7a plots the Weber number as function of the average surface roughness. This is based on research by Roisman et al. ${ }^{3}$, who plotted the Weber number as function of the slope of the roughness profile. A linear transition area corresponding to a splashing threshold can be observed with our experimental results. Earlier work by Mundo et al. ${ }^{10}$ states already that not only the fluid parameters and the kinematics are involved in deformation, spreading and splashing of drops, but that the ratio between the surface roughness and the drop diameter plays a role on the impact behaviour. Thus in figure $7 \mathrm{~b}$ we plot the splashing parameter, $\mathrm{K}$, as function of the average surface roughness, Sa, divided by the initial drop diameter, $\mathrm{D}_{0}$. This dimensionless approach shows again a clear splashing threshold. The non-splashing and splashing impacts, as observed with the high-speed recordings, are shown in different colours to visualise the different regimes. Slight overlap between non-splashing and splashing cases is found close to the limit. For surface (I), with an average 
a)

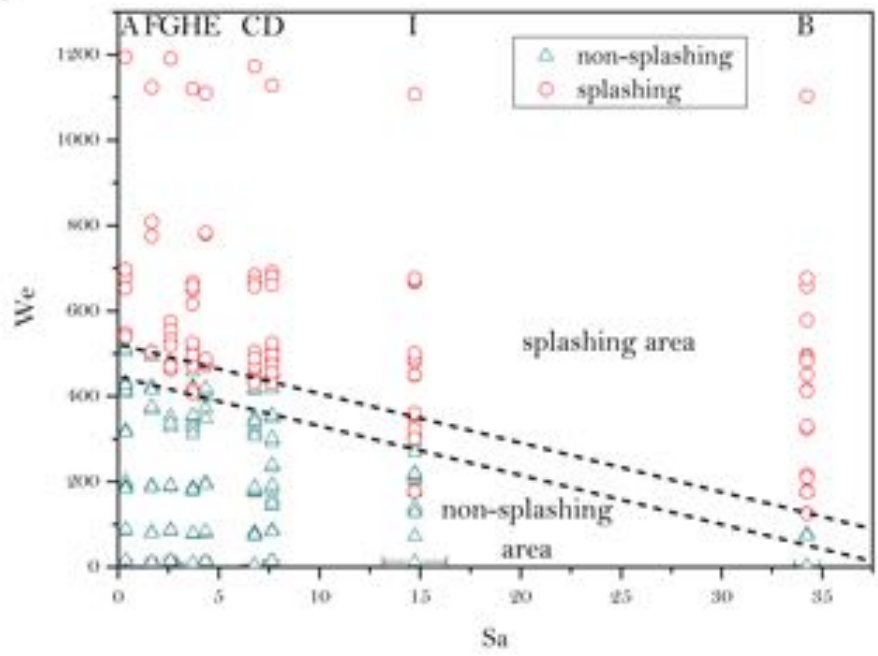

b)

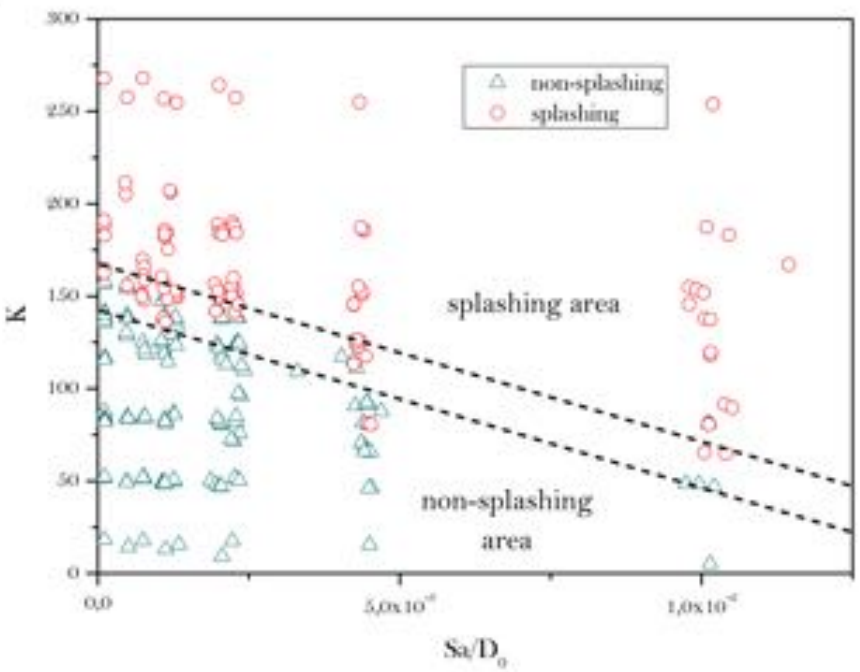

Figure 7: Splashing limit based on high-speed recordings. For splashing, at least secondary stain was observed. For clarity reasons the error bars for the surface roughness are only shown for the lowest impact velocities. a) Weber number as a function of roughness (corresponding surfaces are indicated on the top part of the graph). b) K number as a function of $\mathrm{Sa} / \mathrm{D}_{0}$.
Sa value of 14.7, splashing is also observed for lower Weber numbers. This is simply caused by a difference in roughness during the drop impact experiments since surface (I) is the surface with the largest standard deviation, and for which the Sa value is the least repeatable. The error bars of the Sa values shown in figure 7a emphasise this deduction, giving support to the hypothesis that the roughness is a really important factor in the splashing threshold of blood drops. This corroborates what was observed for Newtonian fluids that splashing is observed at lower velocities for rougher substrates. The explanation for this can be found in the amount of air that has to escape during drop impact. Given for rougher surfaces, characterised by higher values of average roughness, Sa, i.e. larger voids, we can assume that more air is entrapped during the early contact. The entrapment of air during impact leads to drop splashing, which can possibly already occur as well at relatively low impact velocities. On figure 8, a comparison between blood and Newtonian fluids of the recent study of Tang et al is presented. Tang et al. used $(\mathrm{We} / \mathrm{Oh})^{1 / 2}$ with Oh the Ohnesorge number, $\mathrm{Oh}=\sqrt{W e} / \mathrm{Re}$, as a splashing parameter and suggested a linear relationship $\left(\mathrm{y}=a+b \ln \left(\mathrm{Sa} / \mathrm{D}_{0}\right)\right.$, with $a$ and $b$ depending on the liquid properties) between this parameter and an increase in surface roughness, as shown with the different dashed lines. To introduce a comparison with blood, the splashing threshold of blood is compared to the splashing threshold of the Newtonian liquids of the study of Tang. An average Oh $\left(\mathrm{Oh}_{\text {ave }}\right)$ is used since blood viscosity cannot be directly estimated. When for Newtonian liquids a linear relationship is observed, figure 8 shows that this linear relationship does not work for blood, a non-Newtonian fluid, since the change in viscosity is not taken into account in the model, but instead two distinct slopes are observed. Since blood has shear thinning properties, it can be deduced that for the entrapped air bubble to escape, rougher surfaces would not ease this mechanism leading to higher shear stress, changing the viscosity. Since the shear stressed induced cannot be measured, a constant blood viscosity is used in figure 8 , which 
explains the change in the slope. We consider

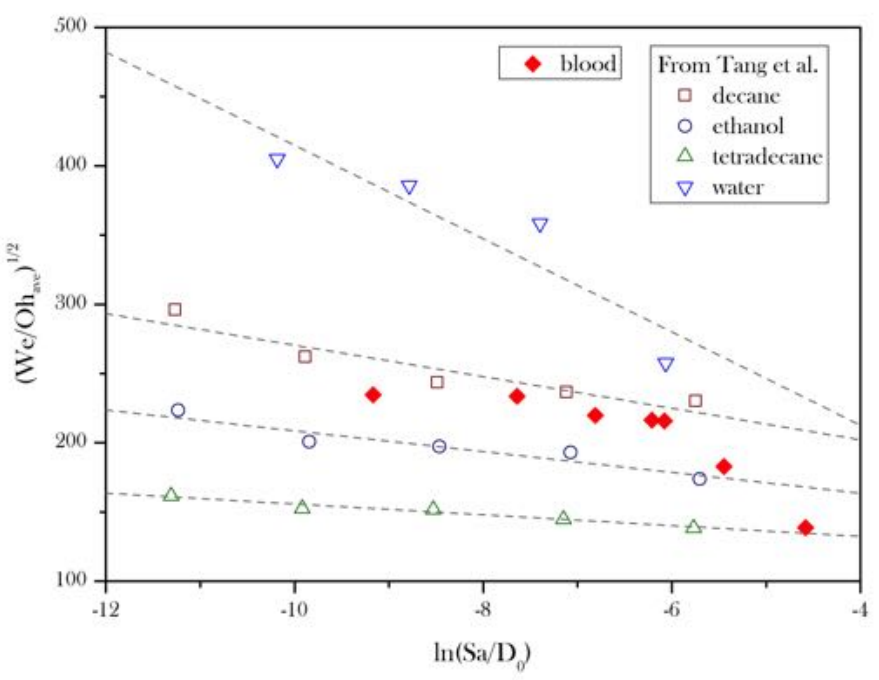

Figure 8: Splashing threshold, with $\left(\mathrm{We} / \mathrm{Oh}_{\text {ave }}\right)^{1 / 2}$ as a splashing parameter, of blood and Newtonian fluids from Tang et al. (2017).

as well the wettability. Since all of the surfaces appear to be hydrophilic, in order to identify the role played solely by the hydrophobicity of the surfaces some of the surfaces are treated with a non-wettable substance, making them hydrophobic. In table 2 the results of this substance can be observed, changing the contact angle to approximately $112^{\circ}$. Neither correlating the contact angles of the surfaces with the observed splashing/non-splashing drop outcomes, nor combining contact angles and roughness with the outcomes leads to conclusive results. Moreover if comparing the surfaces without the non-wettable substance to the ones on which we apply the three layers of the substance, the splashing threshold is not affected. Hence for the same roughness, but different wettability, the same splashing threshold is observed, implying that roughness is a key factor having an influence on the splashing/nonsplashing transition. These observations are in line with what is expected: that the roughness is the main parameter controlling the pattern, whereas wettability would influence this threshold only for vey smooth surfaces, such as glass, where the role of roughness is no longer significant as described in recent studies ${ }^{28,19}$ confirming the influence of wettability for very smooth surfaces on the spreading of liquids at low veloc- ities. Additionally, on superhydrophobic surfaces, liquid drops tend to bounce, which will support the fact that wettability could in turn play a role on the splashing threshold of very smooth surfaces. Hence, it can be assumed that the role played by wettability on the splashing threshold would find significance only for very smooth surfaces, when roughness has not yet determined the outcome. Since our focus is to serve forensic applications and that drop impacts were at atmospheric pressure, the effect of the surrounding gas on the splashing/nonsplashing threshold of blood is not quantified. This first part of our discussion describes the parameters involved at drop impact, and the role they play on the splashing threshold, accounting for an important part of understanding blood drop impact phenomena.

\section{Influence on the drip stains pattern}

After evaluating the influence of drop velocity and surface roughness on the physics involved at impact and in particular the splashing threshold, we consider next how they influence the outcome of the final patterns after impact, which is even more relevant to forensic analysis. With the high-speed recordings we were able to classify our impacting droplets as either splashing or non-splashing. But what can be observed with the high velocity camera, is not always visible after impact, by only photographing the drip stain features. Thus with the pictures taken right after impact of the blood drip stains, we create the visual representation given in figure 9 which shows the appearance of the stains, from a top-view, ordered according to their impact velocities and the roughness properties of surfaces. The roughness has already been shown to be a key parameter playing a role in the behaviour of impacting blood droplets. From left to right, the arithmetic average of the surface roughness increases, thereby indicating smooth surfaces on the left and rough surfaces on the right of the figure. As can be seen, drop impacts on the smooth surfaces result in stains with smooth edges, no deformation and only some satellite stains at higher impact velocities. The two roughest surfaces, (B) and (I), 


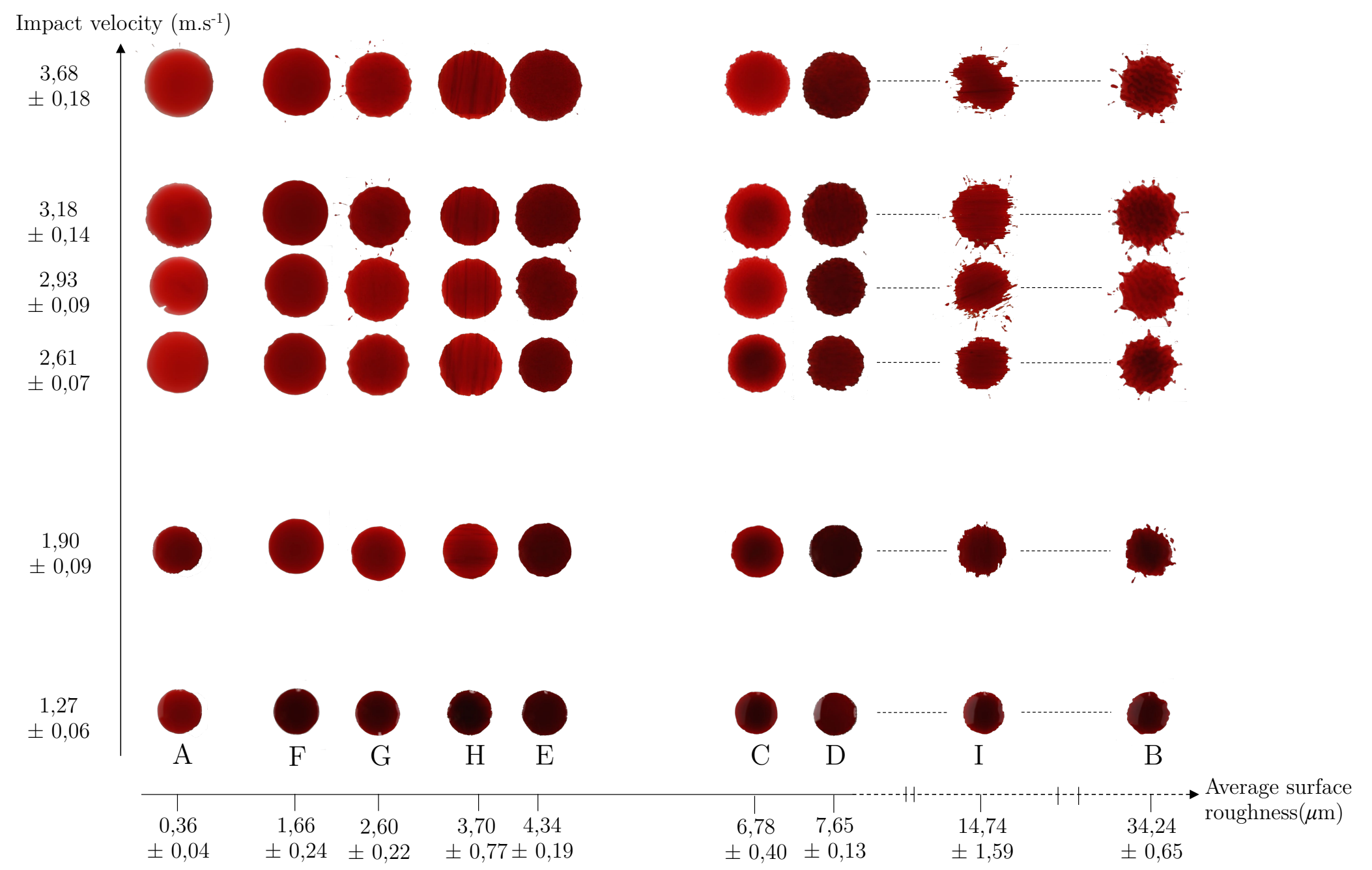

Figure 9: Recorded pictures just after impact of the passive drip stains. Deformation of the stain is increasing with velocity, from bottom to top, and with rough surfaces (cf table 2), from right to left (scaled axis). 
show clearly deformed edges, where a nice circular shape cannot be identified: large irregularities are visible on the edges of the parent stain. In between the smooth and rough substrates, surfaces G, H, E, C and D show some small deformations around the circular edge, in the form of scallops, although the circular structure remains clearly visible. As expected, rough surfaces present clearly visible satellite stains, but surface $(\mathrm{G})$ appears to have its satellite stains clearly visible as well, unlike the other surfaces of similar roughnesses. However, this only means that the satellite stains for this surface are of a larger volume than for the other surfaces of similar roughness, and thus become visible with a top-view picture. For the other surfaces the satellite stains are too small. Moreover, the edge of the parent stain is not really deformed. Hence, the surface roughness not only influences the splashing limit, but also is of major influence in the smoothness of the edge of the parent stain. Additionally, the irregularity of the parent stain seems to increase with impact velocity: the higher the impact velocity, the more irregular this edge will be. This, as well as the increasing diameter, is in line with the observations in earlier publications $^{29,30}$. One assumption to explain these observations is that the rougher the surface is, the more difficult it will be for the entrapped air to escape. On very smooth surfaces, the skating on a thin air layer would favour fingeringlink splashing, whereas on rough surface, more stress would act on blood, changing its viscosity, and the splashing would resemble more a corona-like splashing. Surface G would correspond to this transition, where large finger-like droplets are observed. Data and observations for the treated surfaces have not been incorporated into this figure. However photos and high-speed recordings have been compared one to one with the drop impacts of the untreated surfaces. We find that wettability does not significantly influence the splashing limit or the appearance of the drip stains presented in figure 9. On the other hand, the pattern of the dried stains exhibit some small differences between the non-treated and treated surfaces, depending on the surface. During drying of the drip stains, two different evaporation regimes take place ${ }^{14}$, where the colloids present in blood are redistributed and the stress induced by the evaporation of water, the main component of plasma, leads to noteworthy cracks. For surface $(\mathrm{C})$ and $(\mathrm{H})$, less cracking is observed for low impact velocity stains when they impacted on treated (hydrophobic) surfaces compared to non-treated (hydrophilic) surfaces. It seems that the wettability of the surfaces plays a role in the drying process, by inducing some stresses on the cracking features of a drying drip stain.

\section{Conclusions and perspectives}

With the aim of answering some current forensic concerns, this study showed that the roughness and the velocity are the two main parameters controlling the post-impact pattern of blood, a non-Newtonian fluid. At low velocities, below $1.5 \mathrm{~m} . \mathrm{s}^{-1}$, on smooth and rough surfaces no splashing and well-defined small circular stains are observed, whereas for high impact velocities, all surfaces show splashing. However at high velocities, as the spreading diameter increases, deformation expressed as a circular spine shape is also observed alongside splashing. While for smooth surfaces the deformation remains low, for rough surfaces, Sa greater than $6 \mu \mathrm{m}$, an important deformation is observed. The wettability seemed to play no significant role in these observations, although it could be more significant for very smooth surfaces such as glass. We have also noted that it might have a small influence on the dried patterns. Further work on this topic will find possible applications in crime scene investigation, by providing the fundamental interpretations to what is observed in forensic situations. Using such knowledge on-site will help accurate reconstitution of events.

Acknowledgement The authors thank the volunteers who gave their blood and Magalie di Nocera, the nurse, who sampled this blood. This work received a financial grant from the French Agence Nationale de la Recherche in the frame of the project ANR-13-BS09-0026. Also, this work has been carried out in the 
framework of the Labex MEC (ANR-10-LABX0092) and of the A*MIDEX project (ANR- 11IDEX-0001-02), funded by the "Investissements d'Avenir" French Government program managed by the French National Research Agency (ANR).

\section{References}

(1) Josserand, C.; Thoroddsen, S. Drop Impact on a Solid Surface. Annual Review of Fluid Mechanics 2016, 48, 365-391.

(2) Rioboo, R.; Marengo, M.; Tropea, C. Time evolution of liquid drop impact onto solid, dry surfaces. Experiments in Fluids 2002, 33, 112-124.

(3) Roisman, I. V.; Lembach, A.; Tropea, C. Drop splashing induced by target roughness and porosity: The size plays no role. Advances in Colloid and Interface Science 2015, 222, 615-621.

(4) Marengo, M.; Antonini, C.; Roisman, I. V.; Tropea, C. Drop collisions with simple and complex surfaces. Current Opinion in Colloid \& Interface Science 2011, 16, 292-302.

(5) Rioboo, R.; Tropea, C.; Marengo, M. Outcomes from a drop impact on solid surfaces. Atomization and Sprays 2001, 11, 12.

(6) Latka, A.; Strandburg-Peshkin, A.; Driscoll, M. M.; Stevens, C. S.; Nagel, S. R. Creation of Prompt and Thin-Sheet Splashing by Varying Surface Roughness or Increasing Air Pressure. Physical Review Letters 2012, 109.

(7) Chamakos, N. T.; Kavousanakis, M. E.; Boudouvis, A. G.; Papathanasiou, A. G. Droplet spreading on rough surfaces: Tackling the contact line boundary condition. Physics of Fluids 2016, 28, 022105.

(8) Tang, C.; Qin, M.; Weng, X.; Zhang, X.; Zhang, P.; Li, J.; Huang, Z. Dynamics of droplet impact on solid surface with different roughness. International Journal of Multiphase Flow 2017, 96, 56-69.

(9) Yarin, A. L. Drop impact dynamics: splashing, spreading, receding, bouncing... Annu. Rev. Fluid Mech. 2006, 38, 159 192.

(10) Mundo, C. H. R.; Sommerfeld, M.; Tropea, C. Droplet-wall collisions: experimental studies of the deformation and breakup process. International journal of multiphase flow 1995, 21, 151-173.

(11) Kabaliuk, N.; Jermy, M.; Morison, K.; Stotesbury, T.; Taylor, M.; Williams, E. Blood drop size in passive dripping from weapons. Forensic Science International 2013, 228, 75-82.

(12) Riddel, J. P.; Aouizerat, B. E.; Miaskowski, C.; Lillicrap, D. P. Theories of Blood Coagulation. Journal of Pediatric Oncology Nursing 2007, 24, 123-131.

(13) Sobac, B. Evaporation de gouttes sessiles : des fluides purs aux fluides complexes. Ph.D. thesis, Aix-Marseille University, 2012.

(14) Brutin, D.; Sobac, B.; Loquet, B.; Sampol, J. Pattern formation in drying drops of blood. Journal of Fluid Mechanics 2011, 667, 85-95.

(15) Miles, H.; Morgan, R.; Millington, J. The influence of fabric surface characteristics on satellite bloodstain morphology. Science \& Justice 2014, 54, 262-266.

(16) De Wael, K.; Lepot, L. Morphological details in bloodstain particles. Forensic Science International 2015, 246, 50-54.

(17) Vafaei, S.; Borca-Tasciuc, T.; Podowski, M. Z.; Purkayastha, A.; Ramanath, G.; Ajayan, P. M. Effect of nanoparticles on sessile droplet contact angle. Nanotechnology 2006, 17, 2523-2527. 
(18) Xu, L.; Zhang, W. W.; Nagel, S. R. Drop Splashing on a Dry Smooth Surface. Physical Review Letters 2005, 94.

(19) Lee, J. B.; Laan, N.; de Bruin, K. G.; Skantzaris, G.; Shahidzadeh, N.; Derome, D.; Carmeliet, J.; Bonn, D. Universal rescaling of drop impact on smooth and rough surfaces. Journal of Fluid Mechanics 2016, 786.

(20) Wildeman, S.; Visser, C. W.; Sun, C.; Lohse, D. On the spreading of impacting drops. arXiv preprint arXiv:1602.03782 2016 ,

(21) de Goede, T. C.; de Bruin, K. G.; Bonn, D. Splashing of impacting drops. arXiv preprint arXiv:1701.02504 2017,

(22) Yarin, A. L.; Weiss, D. A. Impact of drops on solid surfaces: self-similar capillary waves, and splashing as a new type of kinematic discontinuity. Journal of Fluid Mechanics 1995, 283, 141.

(23) Antonini, C.; Amirfazli, A.; Marengo, M. Drop impact and wettability: From hydrophilic to superhydrophobic surfaces. Physics of Fluids 2012, 24, 102104.

(24) $\mathrm{Xu}, \mathrm{L}$. Liquid drop splashing on smooth, rough, and textured surfaces. Physical Review E 2007, 75.

(25) Palacios, J.; Gómez, P.; Zanzi, C.; López, J.; Hernández, J. Experimental study on the splash/deposition limit in drop impact onto solid surfaces. Proceedings of 23rd ILASS-2010, Brno, Czech Republic 2010,

(26) Wal, R. L. V.; Berger, G. M.; Mozes, S. D. The splash/non-splash boundary upon a dry surface and thin fluid film. Experiments in Fluids 2006, 40, 53-59.

(27) Vander Wal, R. L.; Berger, G. M.; Mozes, S. D. The combined influence of a rough surface and thin fluid film upon the splashing threshold and splash dynamics of a droplet impacting onto them. Experiments in Fluids 2006, 40, 23-32.
(28) Laan, N.; de Bruin, K. G.; Bartolo, D.; Josserand, C.; Bonn, D. Maximum Diameter of Impacting Liquid Droplets. Physical Review Applied 2014, 2.

(29) Range, K.; Feuillebois, F. Influence of surface roughness on liquid drop impact. Journal of Colloid and Interface Science 1998, 203, 16-30.

(30) Stotesbury, T.; Taylor, M. C.; Jermy, M. C. Passive Drip Stain Formation Dynamics of Blood onto Hard Surfaces and Comparison with Simple Fluids for Blood Substitute Development and Assessment'. Journal of Forensic Sciences 2017, 62, 74-82. 